See Article page 1864.

\section{Commentary: One size fits most, but not all when discontinuing direct oral anticoagulants before cardiac surgery}

Robert S. Kramer, MD, and Wesley Zemrak, PharmD

The manuscript entitled "Protocol for Safe Management of Patients Under Direct Oral Anticoagulant Therapy Before Cardiothoracic Surgery Compared With Patients Undergoing Vitamin K Antagonist or No Anticoagulation Therapy" "outlines how an applied protocol allowed anticoagulated patients on direct oral anticoagulants (DOACs) to undergo major cardiac surgery as safely as those on vitamin $\mathrm{K}$ antagonists (VKAs). The timing of discontinuing direct thrombin inhibitors and factor Xa inhibitors before cardiac surgery is currently variable in and between centers. This analysis adds to the evidence supporting readiness for surgery guidelines in an era in which preoperative patients requiring oral anticoagulant therapy are taking DOACs more often than the traditional VKAs. The authors have concluded that discontinuing the DOAC 4 days before admission for cardiac surgery appears to be a safe way to avoid hemorrhagic complications of cardiac surgery, providing that there is an accurate history.

Discontinuing the anticoagulant (without bridging) 4 days before surgery (surgery being day zero) combined with a measurement of the DOAC on the day before surgery regardless of the DOAC with a defined no-go threshold $(<30 \mathrm{ng} / \mathrm{mL}$ for both direct thrombin inhibitors and anti-Xa drugs) offers a high degree of safety with regard to hemorrhagic complications in the perioperative setting of cardiac surgery, as the authors were unable to detect any difference in outcome measures between the VKA antagonist and DOAC groups.

In 75 of 487 patients $(15 \%)$, the drug levels were $>30 \mathrm{ng} / \mathrm{mL}$ on the day before scheduled surgery. In total, $59 \%$ of those patients had taken their DOAC despite their physicians advising them otherwise. This strategy fits most patients, but not all, as $85 \%$ of the patients in this study were able to have cardiac surgery safely after

From the Maine Medical Center Cardiovascular Institute, Portland, Me.

Disclosures: Authors have nothing to disclose with regard to commercial support.

Received for publication Dec 9, 2019; revisions received Dec 9, 2019; accepted for publication Dec 10, 2019; available ahead of print Jan 7, 2020.

Address for reprints: Robert S. Kramer, MD, Maine Medical Center Cardiovascular Institute, 22 Bramhall St, Portland, ME 04102 (E-mail: kramer@mmc.org).

J Thorac Cardiovasc Surg 2021;161:1875

$0022-5223 / \$ 36.00$

Copyright (c) 2020 by The American Association for Thoracic Surgery

https://doi.org/10.1016/j.jtcvs.2019.12.041

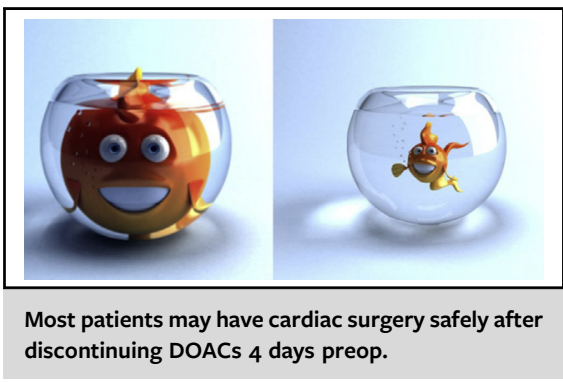

CENTRAL MESSAGE

Most of the patients undergoing cardiac surgery should be safe with a DOAC hold time 4 days before the procedure, providing a thorough history is taken.

discontinuing DOACs 4 days before their operation. The other $15 \%$ were postponed until their drug levels became lower than the $30 \mathrm{ng} / \mathrm{mL}$ threshold.

The question remains as how to generalize this study for centers in which the laboratories do not provide the testing done in this study to safely manage the other $15 \%$. A careful history may find most of the patients who continued to take their DOAC longer than advised. In the absence of testing, there may remain a few patients who will be at risk for being above the $30 \mathrm{ng} / \mathrm{mL}$ drug level used in this study. There remains a paucity of data regarding DOAC drug levels and a correlation with clinically significant bleeding; therefore, the use of a specific "go or no-go" threshold for surgery is difficult to determine. In the recently published Perioperative Anticoagulation Use for Surgery Evaluation (PAUSE) cohort study, ${ }^{2} 1119$ of 3007 (37.2\%) of patients underwent cardiothoracic surgery just 2 days after discontinuing DOACS, with a major bleeding rate of $<3 \%$. Furthermore, drug levels obtained before the procedure (but not known at the time of the procedure) showed that $>90 \%$ of patients had levels $<50 \mathrm{ng} / \mathrm{mL}$ and $>85 \%$ had levels $<30 \mathrm{ng} / \mathrm{mL}$, illustrating that most of the patients undergoing these high-bleed risk procedures should be safe with a DOAC hold time between 2 and 4 days before the procedure.

\section{References}

1. Fox V, Kleikamp A, Dittrich M, Zittermann A, Flieder T, Knabbe C, et al Direct oral anticoagulants and cardiac surgery: a descriptive study of preoperative management and postoperative outcomes. J Thorac Cardiovasc Surg. 2021;161: 1864-74.e2.

2. Douketis JD, Spyropoulos AC, Duncan J, Carrier M, Le Gal G, Tafur AJ, et al, Perioperative management of patients with atrial fibrillation receiving a direct oral anticoagulant. JAMA Intern Med. 2019;179:1469-78. 